Portland State University

PDXScholar

Economics Faculty Publications and

Presentations

Economics

$12-1-2015$

\title{
Insurance, Race/Ethnicity, and Sex in the Search for a New Physician
}

\author{
Rajiv Sharma \\ Portland State University \\ Arnab Mitra \\ Portland State University \\ Miron Stano \\ Oakland University
}

Follow this and additional works at: https://pdxscholar.library.pdx.edu/econ_fac

Part of the Health Economics Commons

Let us know how access to this document benefits you.

\section{Citation Details}

Sharma, Rajiv; Mitra, Arnab; and Stano, Miron, "Insurance, Race/Ethnicity, and Sex in the Search for a New Physician" (2015). Economics Faculty Publications and Presentations. 39.

https://pdxscholar.library.pdx.edu/econ_fac/39

This Post-Print is brought to you for free and open access. It has been accepted for inclusion in Economics Faculty Publications and Presentations by an authorized administrator of PDXScholar. Please contact us if we can make this document more accessible: pdxscholar@pdx.edu. 


\title{
Insurance, Race/Ethnicity, and Sex in the Search for a New Physician
}

\author{
Rajiv Sharma (Corresponding author) \\ Department of Economics \\ P.O. Box 751 \\ Portland State University \\ Portland, OR 97207 \\ sharmar@pdx.edu \\ Arnab Mitra \\ Department of Economics \\ Portland State University \\ amitra@pdx.edu \\ Miron Stano \\ Department of Economics \\ Oakland University \\ stano@oakland.edu
}

\begin{abstract}
$\underline{\text { Abstract }}$
We employed simulated patient calls to a national random sample of primary care physicians to assess appointment availability for adults who differed by insurance, race/ethnicity, and sex. The disparities we found are much larger than those reported in previous assessments, highlighting the importance of including race/ethnicity and sex in such research.
\end{abstract}

JEL Classifications: C9, I1.

Keywords: Field experiment; disparities; access to primary care. 


\section{Insurance, Race/Ethnicity, and Sex in the Search for a New Physician}

\section{Introduction}

A better understanding of the magnitudes and sources of health disparities remains a major research challenge. Following 1999 federal legislation, the Agency for Healthcare Research and Quality (AHRQ) has monitored disparities in access since 2003. Although some improvements were identified in recent reports, access worsened for many groups between 2000-2002 and 2010-2011 (AHRQ, 2014). While minorities typically experience worse access than whites on a panel of established access measures adopted by AHRQ, poor households in 2012 had worse access than highincome households on every measure. Differences in access are associated with greater ill health and mortality among disadvantaged populations.

Simulated consumer studies (audits) have examined the effects of race/ethnicity, sex, age, and disability in markets including employment, housing, and cars (e.g., Neumark, 1996; Bertrand and Mullainathan, 2004; Yinger, 1986; Ayres and Siegelman, 1995). However, audits in health economics remain rare (Hansen et. al., 2013) and limited to assessments of appointment availability and the effects of insurance (e.g., Rhodes et al. 2014). None have examined the effects of race/ethnicity and sex.

We employed simulated patient calls in Summer/Fall 2013 to the offices of a national random sample of primary care physicians to assess appointment availability for white, black, and Hispanic women and men with different types of insurance. This is the first audit study to sample primary care physicians nationally, to examine the effect of race/ethnicity and sex on access, and to assess appointment offers for Medicare patients. The disparities we found adversely affecting some subgroups of Medicaid patients are much larger than in previous assessments of primary care appointments. These should be a cause for heightened concern among policymakers, and highlight the importance of including race/ethnicity and sex in such research.

\section{Methods}

Student research assistants (RAs) telephoned the offices of 1,888 physicians from a random sample of the AMA's Physician Masterfile, a comprehensive listing of licensed US physicians. The sample was restricted to active physicians specializing in family medicine, general practice, general practice medicine, urgent care, or internal medicine. Each physician was randomly assigned a patient profile reflecting insurance type ("traditional" Medicare, Medicaid, private, and self-pay) and one of 18 patient names that signaled race/ethnicity. Thirty physicians were assigned to each profile without regard to the proportion of the population represented by that profile (i.e., no stratification). We could not call 272 physicians with unidentifiable office phone numbers. We considered an appointment as having been offered if the physician's office provided a possible appointment date or date range with either the physician or an alternate, and confirmed that payment from one or more plans from the patient's insurance type was accepted.

We adapted methods from Bertrand and Mullainathan (2004) and generated three male and female names each for blacks, whites, and Hispanics. For black and white first names, we selected those reported by Bertrand and Mullainathan as perceived most distinctly black and white. Black and white last names were selected from among those they listed as "more African-American sounding" or "more white sounding". For Hispanics, we selected the highest ranked first names common among the 5 US 
cities in Lavender's (1988) lists of the most frequent Hispanic names. The Hispanic last names selected were those where the highest proportion of householders self-identified as Hispanic in the 1990 census. We assigned patients with Hispanic names two last names reflecting the common practice of using both maternal and paternal last names in Spanish-speaking societies. Examples of names generated include Tanisha Washington, Anne Baker, Maria Garcia-Gonzalez, Kareem Robinson, Greg O’Brian, and Juan Martinez-Hernandez.

RAs called physicians' offices for information regarding the earliest available appointment for a physical exam for a healthy adult. They called on behalf of purported uncles or aunts to permit them to represent patients whose demographic characteristics differed from those indicated by RAs' voices. Table $1 \mathrm{~A}$ in the web-only appendix summarizes call methods.

We obtained appointment/availability information from 1406 physicians' offices. Our analysis excludes 233 self-reported specialists and another 251 physicians for various other reasons (e.g., works in a closed-model HMO, treats only special populations such as veterans, and treats only populations with special needs such as diabetics and weight-loss patients). Of the remaining 922, 440 offered appointments with the physician called (378), an alternate (63), or both.

We estimated 3 regression models for both probability of appointment offers (logistic) and wait-toappointment (linear on log-transformed days to appointment) to examine the effects of dividing nonwhite and Medicaid patients into successively finer sub-groups. Independent variables in all regressions included indicators for the month and day of week when the call was completed, as well as caller fixed effects. Data on wait-to-appointment were highly skewed and a Box-Cox analysis indicated that a logarithmic transformation would be appropriate.

\section{Results}

Medicaid patients were less likely to be offered appointments (27\%) than those with other types of insurance (Table 1). Medicare patients were offered appointments (52\%) at almost twice the Medicaid rate and at about the same rate as patients with private insurance. Self-pay patients $(61 \%)$ were offered appointments at the highest rate among the insurance groups.

Blacks, whites and Hispanics were offered appointments, respectively, $45 \%, 50 \%$, and $48 \%$ of the time. The racial/ethnic differences were not statistically significant. Non-white women on Medicaid were least likely to be offered appointments (20\% for blacks, $14 \%$ for Hispanics). Self-pay white men $(70 \%)$ had the highest rate of appointment offers.

Medicaid patients had longer waits-to-appointments than those with other types of insurance (37 days). Blacks, whites, and Hispanics had mean waits of 18, 26, and 23 days, respectively. The racial/ethnic differences were not statistically significant. Black women on Medicaid had the longest waits (70 days). 
Table 1

Summary statistics. Appointment offers.

\begin{tabular}{|c|c|c|c|c|}
\hline \multirow[b]{2}{*}{ Patient Group } & \multirow[b]{2}{*}{ Obs } & \multirow[b]{2}{*}{ Probability of Offer } & \multicolumn{2}{|c|}{ Wait-to-Appointment } \\
\hline & & & Mean & Std. Dev \\
\hline All & 922 & 0.48 & 22 & 35.5 \\
\hline Male & 463 & 0.51 & 24 & 38.9 \\
\hline Female & 459 & 0.45 & 21 & 31.9 \\
\hline Black & 317 & 0.45 & 18 & 28.6 \\
\hline White & 308 & 0.5 & 26 & 40.4 \\
\hline Hispanic & 297 & 0.48 & 23 & 36.6 \\
\hline Medicaid & 243 & 0.27 & 37 & 47.9 \\
\hline Medicare & 239 & 0.52 & 24 & 35.4 \\
\hline Self-pay & 205 & 0.61 & 17 & 36.4 \\
\hline Private Ins. & 235 & 0.53 & 19 & 24.4 \\
\hline White male self-pay $^{+}$ & 30 & 0.70 & 31 & 73.9 \\
\hline Hispanic female private ins. ${ }^{++}$ & 34 & 0.53 & 9 & 9.7 \\
\hline Hispanic female Medicaid & 37 & 0.14 & 51 & 61.3 \\
\hline Black female Medicaid "- & 46 & 0.20 & 70 & 82.8 \\
\hline
\end{tabular}

Wait-to-appointment measured in days. ${ }^{+}$subgroup with highest probability of appointment offer. ${ }^{++}$subgroup with lowest wait-to-appointment. " subgroup with lowest probability of appointment offer. "'subgroup with highest wait-toappointment.

Logistic model 1 (Table 2) shows that Medicaid reduced the probability of appointment offers, and that women were less likely to be offered appointments. Compared to whites, blacks and Hispanics received fewer appointment offers, but the effects were not statistically significant. Estimating race/ethnicity and sex groups separately for Medicaid patients (model 2), the disadvantage for women applied to blacks and Hispanics only (statistically significant for black women, but not for Hispanic women). When Medicaid subgroups were further subdivided (model 3), the Medicaid disadvantage (now the effect for white men) was diminished.

Wait time regressions found that Medicaid increased waits in all models. Other effects were statistically significant only in model 6 where waits were shorter for black men on Medicaid and longer for black women on Medicaid. 
Table 2

Regression analysis of associations between appointment offers and patient characteristics.

\begin{tabular}{|c|c|c|c|c|c|c|}
\hline \multirow[b]{2}{*}{ Fixed Effects } & \multicolumn{3}{|c|}{ Probability of Offer (logit) } & \multicolumn{3}{|c|}{$\ln$ (Wait-to-Appointment) (OLS) } \\
\hline & 1 & 2 & 3 & 4 & 5 & 6 \\
\hline Medicaid & $\begin{array}{c}-1.26 * * * \\
(0.20)\end{array}$ & $\begin{array}{c}-1.25 * * * \\
(0.20)\end{array}$ & $\begin{array}{c}-0.86^{* * *} \\
(0.39)\end{array}$ & $\begin{array}{c}0.71 * * * \\
(0.21)\end{array}$ & $\begin{array}{c}0.71 * * * \\
(0.22)\end{array}$ & $\begin{array}{c}1.03 * * * \\
(0.40)\end{array}$ \\
\hline Medicare & $\begin{array}{l}-0.08 \\
(0.19)\end{array}$ & $\begin{array}{l}-0.08 \\
(0.19)\end{array}$ & $\begin{array}{l}-0.08 \\
(0.19)\end{array}$ & $\begin{array}{c}0.23 \\
(0.17)\end{array}$ & $\begin{array}{c}0.23 \\
(0.17)\end{array}$ & $\begin{array}{c}0.22 \\
(0.17)\end{array}$ \\
\hline Self-Pay & $\begin{array}{c}0.26 \\
(0.20)\end{array}$ & $\begin{array}{c}0.26 \\
(0.20)\end{array}$ & $\begin{array}{c}0.26 \\
(0.20)\end{array}$ & $\begin{array}{l}-0.22 \\
(0.18)\end{array}$ & $\begin{array}{l}-0.21 \\
(0.18)\end{array}$ & $\begin{array}{l}-0.22 \\
(0.17)\end{array}$ \\
\hline Female & $\begin{array}{c}-0.29 * * \\
(0.14)\end{array}$ & $\begin{array}{c}0.08 \\
(0.24)\end{array}$ & $\begin{array}{c}0.14 \\
(0.28)\end{array}$ & $\begin{array}{c}0.05 \\
(0.13)\end{array}$ & $\begin{array}{c}0.08 \\
(0.22)\end{array}$ & $\begin{array}{c}0.18 \\
(0.24)\end{array}$ \\
\hline Black & $\begin{array}{l}-0.27 \\
(0.17)\end{array}$ & $\begin{array}{c}0.02 \\
(0.24)\end{array}$ & $\begin{array}{c}0.12 \\
(0.28)\end{array}$ & $\begin{array}{l}-0.11 \\
(0.16)\end{array}$ & $\begin{array}{l}-0.11 \\
(0.22)\end{array}$ & $\begin{array}{c}0.09 \\
(0.24)\end{array}$ \\
\hline Hispanic & $\begin{array}{l}-0.17 \\
(0.17)\end{array}$ & $\begin{array}{c}0.10 \\
(0.24)\end{array}$ & $\begin{array}{c}0.26 \\
(0.28)\end{array}$ & $\begin{array}{l}0.00 \\
(0.16)\end{array}$ & $\begin{array}{c}0.05 \\
(0.22)\end{array}$ & $\begin{array}{c}0.14 \\
(0.24)\end{array}$ \\
\hline Black female & & $\begin{array}{l}-0.57^{*} \\
(0.34)\end{array}$ & $\begin{array}{l}-0.62 \\
(0.39)\end{array}$ & & $\begin{array}{c}0.00 \\
(0.32)\end{array}$ & $\begin{array}{l}-0.38 \\
(0.35)\end{array}$ \\
\hline Hispanic female & & $\begin{array}{l}-0.54 \\
(0.34)\end{array}$ & $\begin{array}{c}-0.52 \\
(0.39)\end{array}$ & & $\begin{array}{l}-0.10 \\
(0.32)\end{array}$ & $\begin{array}{l}-0.22 \\
(0.34)\end{array}$ \\
\hline Black Medicaid & & & $\begin{array}{l}-0.35 \\
(0.55)\end{array}$ & & & $\begin{array}{c}-1.17 * * \\
(0.57)\end{array}$ \\
\hline Hispanic Medicaid & & & $\begin{array}{l}-0.60 \\
(0.56)\end{array}$ & & & $\begin{array}{l}-0.45 \\
(0.60)\end{array}$ \\
\hline Female Medicaid & & & $\begin{array}{l}-0.17 \\
(0.54)\end{array}$ & & & $\begin{array}{l}-0.55 \\
(0.56)\end{array}$ \\
\hline Black female Medicaid & & & $\begin{array}{c}0.12 \\
(0.80)\end{array}$ & & & $\begin{array}{c}2.41 * * * * \\
(0.86)\end{array}$ \\
\hline Hispanic female Medicaid & & & $\begin{array}{l}-0.37 \\
(0.86)\end{array}$ & & & $\begin{array}{c}0.72 \\
(0.96)\end{array}$ \\
\hline Observations & 922 & 922 & 922 & 440 & 440 & 440 \\
\hline R-squared & & & & 0.08 & 0.08 & 0.10 \\
\hline
\end{tabular}

White males with private insurance are the reference category in all 6 regressions (columns). Standard errors in parentheses. Regressions included controls (not shown, available in web-only appendix) for the month and day of week when call was completed, caller fixed effects, and a constant.

$*_{p}<0.1$.

$* * p<0.05$.

$* * * p<0.01$.

\section{Discussion and Conclusions}

We found substantial disparities, up to five-fold differences in appointment offers, between groups based on insurance, race/ethnicity, and sex. These disparities are much larger than reported by previous survey or audit-based studies. An analysis of the National Ambulatory Medical Care Survey found that two-thirds of primary care physicians reported accepting new Medicaid patients in 2011-12 (Decker, 2013). Rhodes et. al. ( 2014) audited practices with Medicaid contracts in 10 states for routine or urgent primary care appointments and found disparities between new Medicaid and privately insured patients (58\% vs. $85 \%$ ) that were smaller than ours. Our longer waits for Medicaid also differ from the similar waits for Medicaid and privately-insured patients reported by Rhodes et al. 
Our research has limitations. We identified physicians as willing to accept new Medicaid or privatelyinsured patients if they accepted new patients from any plan within these categories. This may overstate access for such patients because specific plans have narrower networks. However, prior findings of similar rates of acceptance for new Medicare and privately-insured patients (Decker, 2011) that closely mirror ours suggest that our relative rates of appointment offers are not biased. To the extent that the greater disparities we found are related to our focus on physical exams for otherwise healthy adults, disparities in preventive care may be greater than in other medical care. Our findings regarding wait-to-appointment for black men and black women on Medicaid should be interpreted cautiously due to the small sample sizes and large variances for these results. However, because these results arise among groups that are historically among the most disadvantaged, they are especially deserving of further investigation.

Our research suggests that audit methods can yield a more complete picture of disparities and that failure to consider race/ethnicity and sex in assessments of access may substantially underestimate disparities. Together with additional rounds of audit data collection, our results can provide useful baseline estimates to evaluate key provisions of the Affordable Care Act.

\section{Acknowledgements}

This research was funded by College of Liberal Arts and Sciences, Portland State University. We thank Kilee Coffelt, Devin Gilbert, Kahela Fickle, Chantha Kim, Raven Susu-Mago, and Amiee Van denBroeke for excellent research assistance. 


\section{References}

Agency for Healthcare Research and Quality. 2014. National Healthcare Disparities Report 2013. Rockville, MD. AHRQ Publication No. 14-0006, May 2014. www.ahrq.gov/research/findings/nhqrdr/index.html. Accessed 10/22/2015.

Ayres, I., Siegelman, P., 1995. Race and Gender Discrimination in Bargaining for a New Car. Am. Econ. Rev. 85,304-21.

Decker, S.,2013. Two-Thirds Of Primary Care Physicians Accepted New Medicaid Patients In 2011-12: A Baseline To Measure Future Acceptance Rates. Health Aff. 32.

Bertrand, M., Mullainathan, S., 2004. Are Emily and Greg More Employable than Lakisha and Jamal? A Field Experiment on Labor Market Discrimination. Am. Econ. Rev. 94,991-1013.

Decker, S., 2012. In 2011 Nearly One-Third Of Physicians Said They Would Not Accept New Medicaid Patients, But Rising Fees May Help. Health Aff (Millwood). 31,1673-9.

Lavender, A., 1988. Hispanic Given Names In Five United States Cities: Onomastics As A Research Tool In Ethnic Identity. Hispanic J Behav Sci. 10,105-25.

Neumark, D., 1996. Sex Discrimination in Restaurant Hiring: An Audit Study. Q J Econ. 111,91541.

Rhodes, K., Kenney, G., Friedman, A., et al. 2014 Primary care access for new patients on the eve of health care reform. JAMA Intern Med. 174,861-9.

Yinger, J., 1986. Measuring Racial Discrimination with Fair Housing Audits: Caught in the Act. Am. Econ. Rev. 76,881-93.

Hansen, F., Anell, A., Gerdthama, U., Lyttkens, C. 2015. The future of health economics: the potential of behavioral and experimental economics. Nordic. J. Health. Econ. 